\title{
The Experience of Emergency Nursing Education for Nursing College Students
}

\author{
Yeon Ja Kim ${ }^{1}$ and Kyung Hwa Jung ${ }^{2}$ \\ ${ }^{1}$ Department of Nursing, Dongseo University, 47, Jurye-ro, Sasang-gu, Busan, 47011, \\ Korea \\ ${ }^{2}$ Department of Nursing, Taegu Science University, 47, Youngsong-ro, Buk-gu, \\ Daegu, 41453, Korea \\ 'yakop1052@gdsu.dongseo.ac.kr
}

\begin{abstract}
To explore the significance of nursing students' experiences of emergency education, a phenomenological research method has been applied to this study and Colaizzi's data analysis method has been used. From May 1st to June 28th, 2019, research data have been collected through interviews with thirteen nursing students in D city. Before data collection, interviews have only been conducted with the students who voluntarily decided to participate in the study after being explained its purpose. Each interview finished when no new themes were observed in the data which was data saturation. As a result, 13 theme clusters and 5 categories have been drawn from 71 meaning formations. The study result has expanded a significant opportunity for recognition of nursing students' emergency experiences. Furthermore, it is expected the result would valuably be utilized to develop more useful emergency education and establish instruction method strategies.
\end{abstract}

Keywords: Nursing college students, Emergency Nursing, Education, Phenomenological research method

\section{Introduction}

\subsection{Necessity of study}

A medical emergency is a very urgent situation directly connected with patients' life, and accordingly professional nursing knowledge and skills would be required in such situations. Notwithstanding, the subject of Emergency Nursing has seldom been assigned as a major course of the Department of Nursing.

Science is, in most cases, classified as an optional subject even when it is included in major courses and nursing students would rarely choose this subject. Clinical emergencies, however, occur frequently despite differences among treatment departments. With a lack of emergency knowledge and skills, therefore, a great part of new nurses tend to be placed in various emergencies, which is one of their main job stressors [1][2]. Hence, an emphasis on education to improve nursing students' emergency coping skills has been growing, which led to the

Article history:

Received (August 26, 2019), Review Result (October 17, 2019), Accepted (November 28, 2019) 
application and implementation of education within simulated emergencies [3][4][5], emergency education [6], and other programs in the education fields as well as nursing colleges' efforts to increase the opportunity of nursing students' acquisition of emergencyrelated certificates. In addition, cardiopulmonary resuscitation (CPR) has recently been included in the 20 Core Basic Nursing Skills provided by the Korean Accreditation Board of Nursing (KABON) for nursing students to learn, and studies of the development of rubrics for assessment of performance practice [7] are being carried out. To enhance the effectiveness of the education, it is essential to actively execute research on the outcomes or/and responses of emergency education for nursing students. Upon examination of previous studies, however, researches of such outcomes were relatively small in number and hardly included the phenomenological research method that is generally applied to investigate the nature of experience. Phenomenological research is useful to understand the empirical nature of emergency education for nursing students.

This study, therefore, is to look into the structure and components of nursing students' experience of emergency education with a phenomenological research method applied.

\section{Method of study}

\subsection{Design of the study}

This study is qualitative research that pursues the significance of nursing students' experience of emergency education with a phenomenological research method applied.

\subsection{Data collection and ethical considerations}

The data collection period of this study was from May $1^{\text {st }}$ to June $28^{\text {th }}, 2019$, and the means of collecting data was depth interview. Before interviews, each nursing student was given a full explanation of the study by a researcher and voluntarily decided whether to participate in the study or not.

\subsection{Participants}

Among nursing students in D city, thirteen of them who voluntarily decided to participate in the study have been selected using convenient sampling after receiving emergency education and being given a detailed explanation of the study by a researcher. All the participants were either in junior or senior year of nursing college, mostly in senior year, which was because professional emergency education is to be provided to senior students to improve their abilities to cope with a clinical emergency before completing nursing college. The participants' general characteristics are shown in [Table 1].

\subsection{Researchers' readiness}

The researchers have been educated in qualitative research since their graduate school years; attended several conferences of international institutes for qualitative methodology as well as the Korean association for qualitative research to promote scholastic exchange with other researchers and improve the standard of qualitative research; and performed multiple qualitative research.

\subsection{Composition of emergency education program}


The emergency education program implemented in this study was developed based on simulation and restructured appropriately for Korean circumstances by the Korean Association of Cardio-Pulmonary Resuscitations about the professional CPR program of the American Heart Association, and has been widely used among nursing and medical students. The education contents were developed to improve healthcare providers' ability to cope with in-hospital cardiac arrest and are composed of a variety of methods of improving a patient's condition by handling his/her cardiac arrest in the short term.

\subsection{Data analysis}

Data analysis of this study was based on Colaizzi's phenomenological research method. Upon completion of data collection, data analysis was immediately performed. Also, interviews continued until the point of data saturation that no new themes were observed.

\section{Result of the study}

As a result of the semantic analysis of nursing students' emergency experiences, 13 theme clusters and 5 categories have been drawn from 71 meaning formations. The result is shown in [Table 1].

Table 1. Theme cluster

\begin{tabular}{|c|c|c|}
\hline Meaning Formation & Theme Cluster & Category \\
\hline Found myself lacking in the proper qualities to be a leader. & \multirow{3}{*}{$\begin{array}{c}\text { The shocking result of } \\
\text { my skills }\end{array}$} & \multirow{12}{*}{$\begin{array}{l}\text { The feeling of } \\
\text { being a burden by } \\
\text { the situation } \\
\text { confronting } \\
\text { confusion }\end{array}$} \\
\hline Realized my abilities realistically. & & \\
\hline Blame me for not being ready. & & \\
\hline Found education difficult. & \multirow{5}{*}{$\begin{array}{l}\text { Being forced to the real } \\
\text { field without getting } \\
\text { ready }\end{array}$} & \\
\hline Feeling stressed from the education. & & \\
\hline Feeling unfamiliar. & & \\
\hline Experienced the feeling of pressure from the exam. & & \\
\hline Being embarrassed not to know what to do. & & \\
\hline Thorough preparation for education is needed. & \multirow{4}{*}{ Ability to be prepared } & \\
\hline Expecting more content on emergency education would be added. & & \\
\hline Communication skill is important. & & \\
\hline Showed my ability while working in a team. & & \\
\hline Started to think of becoming an ER nurse. & \multirow{3}{*}{$\begin{array}{c}\text { Being more interested in } \\
\text { emergency }\end{array}$} & \multirow{6}{*}{$\begin{array}{l}\text { Stepping forward } \\
\text { to be a professional } \\
\text { healthcare provider }\end{array}$} \\
\hline Motivated to study hard. & & \\
\hline Started to think of emergencies critically. & & \\
\hline Started to participate in clinical practicum more actively. & \multirow{3}{*}{$\begin{array}{l}\text { Being more skillful in } \\
\text { clinical practicum }\end{array}$} & \\
\hline Got help from others during clinical practicum. & & \\
\hline Became more interested in clinical practicum. & & \\
\hline
\end{tabular}




\begin{tabular}{|c|c|c|}
\hline Feeling no more helplessness. & \multirow{11}{*}{$\begin{array}{l}\text { Found myself growing } \\
\text { up. }\end{array}$} & \\
\hline Encouraged to challenge new things. & & \\
\hline Became energetic enough to cope with the emergency. & & \\
\hline Being more interested in emergencies. & & \\
\hline Getting more prepared to be a healthcare provider. & & \\
\hline Acquired knowledge enough to teach friends. & & \\
\hline Corrected and fixed my weakness. & & \\
\hline Found myself changing actively. & & \\
\hline Gained confidence during education. & & \\
\hline Realized the value of life. & & \\
\hline Got a sense of duty as a future healthcare provider. & & \\
\hline Basic education for nursing students to be well-acquainted with. & \multirow{6}{*}{$\begin{array}{l}\text { Stepping forward from a } \\
\text { shortage }\end{array}$} & \multirow{22}{*}{$\begin{array}{l}\text { Change from } \\
\text { boring education to }\end{array}$} \\
\hline Essential quality to get a job. & & \\
\hline The privilege of healthcare providers. & & \\
\hline Realized my shortcomings. & & \\
\hline Feeling a sense of pressure from frequent emergencies. & & \\
\hline Lack of confidence. & & \\
\hline Want to receive an intensive level of emergency education? & \multirow{6}{*}{$\begin{array}{l}\text { Learning From } \\
\text { Responsibility }\end{array}$} & \\
\hline Must do my part in an emergency. & & \\
\hline $\begin{array}{l}\text { Feeling a sense of pressure of thinking I have to cope with } \\
\text { emergency successfully. }\end{array}$ & & \\
\hline Want to fulfill my role. & & \\
\hline Want to get training to cultivate leadership? & & \\
\hline The urgency of the emergency that I eye-witnessed. & & \\
\hline Felt it like a real-world situation. & \multirow{5}{*}{$\begin{array}{l}\text { Hands-on experience } \\
\text { with emergencies }\end{array}$} & \\
\hline Felt like the education was very practical and necessary. & & \\
\hline An emergency in that no slight mistake is allowed. & & \\
\hline A simulated emergency that felt realistic. & & \\
\hline Feeling comfortable after experiencing a simulated emergency. & & \\
\hline Caught much attention from various instructors. & \multirow{5}{*}{$\begin{array}{l}\text { Satisfactory educational } \\
\text { contents }\end{array}$} & \\
\hline Had the benefit of systematical education in a small group. & & \\
\hline Systematical education is available within a short time. & & \\
\hline Well-organized education with no waste of time. & & \\
\hline Well-balanced between theory and practice. & & \\
\hline
\end{tabular}




\begin{tabular}{|c|c|c|}
\hline The feeling of relief in a simulated situation. & & \\
\hline Built up trust in professional education. & & \\
\hline Gradually forgot the educational contents as time passed. & \multirow{3}{*}{$\begin{array}{l}\text { The necessity of repeated } \\
\text { education }\end{array}$} & \multirow{13}{*}{$\begin{array}{l}\text { Level up from } \\
\text { beginner }\end{array}$} \\
\hline Getting better through repeated learning & & \\
\hline Realized the importance of continuous education. & & \\
\hline A big barrier to ECG & \multirow{7}{*}{ Barriers to getting over } & \\
\hline Many of the contents felt very difficult. & & \\
\hline The feeling of pressure on the amount of education. & & \\
\hline Development of various educational contents is required. & & \\
\hline Feeling burdened as a leader. & & \\
\hline Education contents are difficult. & & \\
\hline $\begin{array}{l}\text { Inconsistency of coping strategies of emergencies between } \\
\text { hospitals. }\end{array}$ & & \\
\hline Lectures are different depending on the instructor. & \multirow{3}{*}{$\begin{array}{l}\text { Educational content to be } \\
\text { upgraded }\end{array}$} & \\
\hline Various ECG rhythm training required & & \\
\hline Wish there would be an education in medicine. & & \\
\hline
\end{tabular}

\section{Conclusion}

This study was conducted to understand the significance of nursing students' experiences of emergency education, and, from 71 meaning formations, the semantic analysis has drawn 13 theme clusters and 5 categories including "Feeling of the burden of the situation confronting in confusion", "Stepping forward to be a professional healthcare provider", "Motives to learn", "Change from boring education to interesting education" and "Level up from beginner." The study result has enlarged the opportunity for awareness of nursing students' experiences of emergency education and is also expected to be widely utilized to develop advanced and effective nursing education of emergency and establish strategies for its teaching method.

\section{References}

[1] Hur-Hyegyeong and Park-Somi, "Effects of simulation-based education, for emergency care of patients with dyspnea, on knowledge and performance confidence of nursing students," Korean Educational Research Association, vol.18, no.1, pp.111-119, (2012) DOI: 10.5977/jkasne.2012.18.1.111

[2] Kang-Ikhwa and Lee-Eunja., "A study on new nurse's job analysis for improvement of efficiently nursing educational curriculum,” Gachon Gil College, vol.29, pp.59-73, (2001)

[3] Hur-Hyegyeong, Park-Somi, Kim-Gigyeong, Jung-Jisu, Choi-Hyangok, Choi-Jihye, and Shin-Yunhui, "Effectiveness of an emergent care management simulation education among senior nursing students according to learning styles," The Journal of the Korea Contents Association, vol.14, no.3, pp.314-327, (2014) DOI: 10.5392/JKCA.2014.14.03.314

[4] Choi-Eunhui and Kwak-Yungyeong, "Factors affecting nursing performances in emergency simulation," International Journal of Multimedia and Ubiquitous Engineering, vol.7, no.2, pp.505-513, (2017) 
The Experience of Emergency Nursing Education for Nursing College Students

[5] Park-Hyeonjeong, "A debriefing experience analysis of neonatal emergency rehabilitation simulation of nursing university students," The Journal of The Korean Society of Maternal and Child Health, vol.12, pp.205-206, (2018)

[6] Do-Eunsu and Kim-Sungu, "Effect of emergency treatment education program for self-leadership, career decision making self-efficacy and nursing performance ability of nursing students," Journal of the Korea Academia-Industrial cooperation Society, vol.19, no.12, pp.636-644, (2018) DOI: 10.5762/KAIS.2018.19.12.636

[7] Hur-Heakung, Park-Somi, Kim-Kikyong, Jung-Jisoo, Shin-Yoonhee, and Choi-Hyangok, "Evaluation of Lasater clinical judgment rubric to measure nursing student' performance of emergency management simulation of hypoglycemia," Journal of Korean critical care nursing, vol.5, no.2, pp.15-27, (2012) 